\title{
The association between psychosocial and medical factors with long-term sexual dysfunction after treatment for colorectal cancer
}

\author{
Kathrin Milbury • Lorenzo Cohen • Rosell Jenkins • \\ John M. Skibber • Leslie R. Schover
}

Received: 4 May 2012 / Accepted: 20 August 2012 /Published online: 5 September 2012

(C) Springer-Verlag 2012

\begin{abstract}
Purpose Colorectal cancer patients usually receive treatments (e.g., pelvic surgery or radiotherapy, colostomy) that increase their risk for sexual problems. Previous research has mainly focused on demographic and medical risk factors. Because little is known about the role of psychosocial variables in sexual dysfunction, this research sought to identify the contribution of demographic, medical, and psychosocial factors to sexual dysfunction using multivariate analyses.

Methods Male and female colorectal cancer survivors ( $N=$ 261 ; mean, 2.5 years post-treatment) completed paper-pencil
\end{abstract}

K. Milbury $\cdot$ L. Cohen $\cdot$ L. R. Schover

Department of Behavioral Science,

The University of Texas MD Anderson Cancer Center,

1155 Herman P. Pressler,

Houston, TX 77030, USA

L. Cohen

Department of General Oncology,

The University of Texas MD Anderson Cancer Center,

1400 Holcombe,

Houston, TX 77030, USA

R. Jenkins

Mental Wellness Services,

505N Sam Houston Parkway E \# 502,

Houston, TX 77060-4032, USA

J. M. Skibber

Department of Surgical Oncology,

The University of Texas MD Anderson Cancer Center,

1140 Herman P. Pressler,

Houston, TX 77030, USA

K. Milbury $(\bowtie)$

Department of Behavioral Science, Unit 1330,

The University of Texas MD Anderson Cancer Center,

P.O. Box 301439, Houston, TX 77230-1439, USA

e-mail: kmilbury@mdanderson.org questionnaires assessing sexual function, psychosocial variables (e.g., depression, social support, body image, and dyadic adjustment), and demographics. Medical information was obtained from patients' self-report and medical records.

Results Multiple regression analyses revealed that older age, having received destructive surgery (i.e., abdominoperineal resection), and poor social support were uniquely and significantly associated with low international index of erectile function scores in men. For women, low female sexual function index scores were significantly associated with older age and poor global quality of life. Men, but not women, with rectal cancer reported worse sexual function compared to those with colon cancer.

Conclusions Sexual dysfunction after colorectal cancer treatment is related to demographic, medical, and psychosocial factors. These associations can help to identify patients at high risk of sexual problems in order to assist restoring sexual functioning if desired.

Keywords Colorectal cancer survivors · Treatment-related sexual dysfunction $\cdot$ Psychosocial risk factors

\section{Introduction}

Although colorectal cancer is the fourth most common malignancy in the USA [1], and about 1 out of 12 current cancer survivors have had treatment for a colorectal tumor [2], research on colorectal cancer survivors' sexual function remains limited. Colorectal cancer survivors usually have treatments that put them at risk for sexual problems, including pelvic surgery and radiotherapy, and systemic chemotherapy. They may be living with a permanent colostomy or coping with frequent diarrhea or leakage of stool [3]. After treatment, $30-40 \%$ of survivors may discontinue sexual 
activity and high percentages ranging from $23 \%$ to $69 \%$ of men and from $19 \%$ to $62 \%$ of women may experience new sexual dysfunctions [4-6]. Prospective studies indicate that other indices of quality of life (QoL) typically improve over time, yet sexual function remains impaired [7-10].

For men, the most commonly reported problem is erectile dysfunction (ED). Men in the age group at risk for colorectal cancer may already suffer from ED related to comorbidities (e.g., diabetes) $[4,11]$. However, surgery for rectal cancer, in particular, often damages autonomic nerves located between the rectum and prostate that direct blood flow into the penis during erection. Attempts have been made to use nervesparing techniques, particularly with the advent of total mesorectal excision [12]. Nevertheless, rates of long-term erectile dysfunction from $59 \%$ to $90 \%$ have been reported [4, 11-14]. Abdominoperineal resection (APR), a surgical procedure that includes creation of a colostomy and complete removal of the rectum and anus, consistently results in higher rates of erection problems than various types of anterior resection with sphincter-saving $[11,15,16]$. Since APR patients are often older and have more comorbidities, however, extent of surgery may not be the only reason for the poorer outcomes $[4$, 17, 18]. Although adjuvant chemotherapy does not increase the risk of male sexual dysfunction [14, 15, 17, 19], adjuvant pelvic radiotherapy or chemoradiation does increase rates of ED [9, 10, 18-20].

Less is known about female sexual problems after colorectal cancer treatment, particularly because older female survivors are often reluctant to complete questionnaires about sexuality [21]. For instance, in six recent surveys, response rates for men ranged from $52 \%$ to $100 \%$ compared to $27 \%$ to $70 \%$ for women $[4,11,12,14,15,22]$. Many postmenopausal women are not sexually active at cancer diagnosis, either because they lack a partner or because their partner is ill or has ED [4, 11, 23, 24]. Women are more likely than men to give up sexual activity after colorectal cancer treatment $[4,11]$. Those who remain active, however, report high rates of symptoms associated with vulvovaginal atrophy, such as dryness and pain with sex (dyspareunia), as well as problems like vaginal stenosis, loss of sexual desire, and interference with sex from fecal incontinence $[4-6,20]$. Rates of female sexual problems, especially dyspareunia, are higher after APR than other types of anterior resection (AR) $[6,25,26]$, and are also increased in women who have adjuvant radiotherapy $[6,9,10,19]$.

Previous research has mainly focused on the physiological impact of cancer treatment. The potential impact of psychosocial variables such as individual and relational adjustment has been neglected [4-7, 9, 11, 15, 23]. This report describes the analysis of a detailed survey of male and female colorectal survivors that included not only medical and demographic factors but also self-report measures of psychosocial characteristics, including mental health, marital adjustment, social support, and body image, and detailed, validated questionnaires assessing male and female sexual function. Because many risk factors for sexual dysfunction share some variance (e.g., all patients who received APR must cope with having an ostomy; younger patients are more likely to be sexually active but may also be more distressed about sexual dysfunction [26]), we have used an exploratory, descriptive approach including both univariate and multivariate analyses. Thus, the goal of this research was to identify demographic, medical, and psychosocial risk factors that explain a significant proportion of the variance in male and female sexual function in colorectal cancer survivors.

\section{Methods}

\section{Procedures}

Study procedures were approved by The University of Texas MD Anderson Cancer Center's (MDACC) Institutional Review Board. Potential participants were identified through the MDACC's Tumor Registry and the computerized appointment system for the Gastrointestinal Clinic. Patients were approached during clinic appointments and asked to complete the questionnaire either during their visit or at home to be returned via mail. Another group of participants identified from the tumor registry were mailed the questionnaires with a cover letter explaining the study. Before data collection, participants signed informed consent documents. The informed consent form was given to the patient during the clinic visit or included in the mailing with the questionnaire. Patients mailing their questionnaires were given an addressed, postage-paid envelope.

\section{Participants}

Patients were eligible if they were 18 years or older, competent in English, diagnosed with colon or rectal cancer stage I-III, and had received surgery at least 6 months earlier and completed all treatment at least 1 month earlier. To ensure sample homogeneity, patients with familial polyposis or hereditary nonpolyposis colon cancer (Lynch syndrome) were excluded because patients with genetically linked colorectal cancers (approximately $8 \%$ of all colorectal cancers) constitute a markedly different population than those with spontaneous cases [27]. We approached 229 patients in the clinic. Of these patients, 14 did not return their survey $(6.1 \%)$, and $10(4.4 \%)$ were ineligible leaving a total of 205 participants $(89.5 \%)$ who met eligibility requirements and completed the questionnaires. An additional 637 patients were mailed questionnaires. The return rate was $21.5 \%$. Out of 137 patients who returned the postal questionnaires, 81 were excluded due to incomplete data on 
the outcome measures $(n=19)$ or failing to meet eligibility criteria $(n=62)$ after review of the medical record (e.g., continued treatment and metastatic disease). Thus, the final sample used for all analyses was 261 patients.

\section{Measures}

Male and female participants completed demographic questions and standardized assessment instruments measuring sexual and psychosocial functioning and QoL.

\section{Main outcome measures}

Sexual functioning for men was assessed with the international index of erectile function (IIEF) [28, 29]. This 15item inventory yields five subscales: erectile function, orgasmic function, sexual desire, intercourse satisfaction, and overall sexual satisfaction. One item also measures frequency of sexual activity. Many researchers have focused on the erectile function subscale, with scores of 26-30 indicating normal erections, $22-25$ mild dysfunction, $17-21$ mild/ moderate erectile dysfunction, 11-16 moderate dysfunction, and 6-10 a severe problem [28]. We used the total score as our outcome measure because cancer treatment disrupts sexual function across the range of domains.

Women completed the female sexual function index (FSFI), a 19-item questionnaire assessing sexual function and satisfaction across five domains including sexual desire, arousal (both subjective and physiological), lubrication, orgasm, satisfaction, and pain [30]. Women with a total score above 26.55 should be classified as sexually functional, with those scoring below the cutoff indicating sexual dysfunction [30].

\section{Secondary outcome and other measures}

The European Organization for Research and Treatment of Cancer (EORTC) Colorectal Cancer-Specific Quality of Life Questionnaire (QLQ-CR38) was also administered [31]. The 38 items assess global QoL, body image concerns, sexual functioning, sexual enjoyment for those who are sexually active, stoma-related problems for stoma patients, and bowel function for non-stoma patients. Despite the name of the "sexual functioning" subscale, it only assesses frequency of sexual interest and activity rather than problems with the sexual response.

Participants also completed the following psychosocial questionnaires: (1) The Center for Epidemiological StudiesDepression (CES-D) Scale is a self-report measure consisting of 20 items focusing on the affective component of depression [32]. A score of $\geq 16$ is considered the cut-off to screen for a depressive disorder. (2) The Brief Symptom Inventory-18 (BSI-18) consists of 18 items assessing psychological distress along dimensions of depression, anxiety, and somatization [33]. (3) The Medical Outcomes Study Social Support Survey (MOS-SSS) is a 20 -item social support questionnaire developed for the chronically ill [34]. Patients rated their perceived availability of emotional/informational support, tangible support, positive interactions, and affectional support. (4) Respondents in a committed relationship completed the Abbreviated Dyadic Adjustment Scale (A-DAS) [35], a seven-item questionnaire measuring relationship satisfaction.

\section{Demographic and medical factors}

Some demographic items (e.g., age and marital status) were included in the questionnaires. Medical data (disease site, stage, time since diagnosis, time since surgery, sphinctersaving or sacrificing resection, and adjuvant therapy) were extracted from patients' charts.

\section{Statistical analysis}

Demographic characteristics, medical factors, and means of the survey variables are presented using descriptive statistics. We used analysis of variance (ANOVA) to examine associations between demographic or medical variables and the sexual outcomes. Patterns of associations between the psychosocial variables (body image, global QoL, CES-D score, BSI-18 total score, MOS-SSS total score, and ADAS score) as well as bowel and stoma functioning and the sexual functioning measures (IIEF total score, FSFI total score, sexual function, and sexual enjoyment) were examined using Pearson's product moment correlation coefficients.

We performed simultaneous multiple regression analyses for the primary sexual outcome measures (IIEF total score for men and FSFI total score for women) and examined the significance tests associated with the beta coefficient of each predictor variable to identify factors that uniquely contribute to the accounted variance of sexual functioning scores in men and women while controlling for the remaining predictor variables in the model [36].

\section{Results}

Sample's demographic and medical characteristics

The characteristics of our sample of 261 patients by gender are presented in Table 1. Based on MDACC's tumor registry, participants' demographics were representative of the institution's patient population. As expected in this age group, men were more likely than women to be in a committed relationship [37]. Compared to women, men were also older, and 
Table 1 Demographic and medical characteristics of study cohort $(N=261)$
$S D$ standard deviation

${ }^{a}$ Number of stomas represent permanent and temporary stomas. For temporary stomas, data was collected before reversal

\begin{tabular}{|c|c|c|c|}
\hline Variable & $\operatorname{Men}(N=144)$ & Women $(N=117)$ & $P$ value \\
\hline Age $($ mean \pm SD) & $63.3 \pm 10.8$ & $60.5 \pm 11.8$ & 0.04 \\
\hline Years since diagnosis (mean \pm SD) & $3.15 \pm 1.6$ & $3.30 \pm 2.53$ & 0.57 \\
\hline Years since treatment (mean $\pm \mathrm{SD}$ ) & $2.63 \pm 1.41$ & $2.42 \pm 1.31$ & 0.12 \\
\hline \multicolumn{4}{|l|}{ Ethnicity $(N, \%)$} \\
\hline $\begin{array}{l}\text { Caucasian } \\
\text { African-American }\end{array}$ & $\begin{array}{l}125(86.8 \%) \\
5(3.5 \%)\end{array}$ & $\begin{array}{l}85(72.6 \%) \\
11(9.4 \%)\end{array}$ & \multirow[t]{3}{*}{0.09} \\
\hline Hispanic & $8(5.6 \%)$ & $14(12.0 \%)$ & \\
\hline Other & $6(4.1 \%)$ & $5(6.0)$ & \\
\hline \multicolumn{4}{|l|}{ Marital status $(N, \%)$} \\
\hline $\begin{array}{l}\text { Married } \\
\text { Widowed }\end{array}$ & $\begin{array}{l}123(85.4 \%) \\
5(3.5 \%)\end{array}$ & $\begin{array}{l}67(57.3 \%) \\
21(17.9 \%\end{array}$ & \multirow[t]{3}{*}{0.0001} \\
\hline Divorced/separated & $10(6.9 \%)$ & $22(18.8 \%)$ & \\
\hline Never married & $6(4.2 \%)$ & $7(6.0 \%)$ & \\
\hline \multicolumn{4}{|l|}{ Education $(N, \%)$} \\
\hline $\begin{array}{l}\text { Less than high school } \\
\text { High school graduate }\end{array}$ & $\begin{array}{l}8(5.6 \%) \\
29(20.1 \%)\end{array}$ & $\begin{array}{l}9(7.8 \%) \\
25(21.6 \%)\end{array}$ & \multirow[t]{4}{*}{0.34} \\
\hline Some college, no degree & $36(25.0 \%)$ & $39(33.6 \%)$ & \\
\hline Four-year college degree & $41(28.5 \%)$ & $24(20.7 \%)$ & \\
\hline Postgraduate degree & $30(20.8 \%)$ & $19(16.4 \%)$ & \\
\hline \multicolumn{4}{|l|}{ Household income $(N, \%)$} \\
\hline $\begin{array}{l}<\$ 25,000 \\
\$ 26,000-50,000\end{array}$ & $\begin{array}{l}24(17.3 \%) \\
36(25.9 \%)\end{array}$ & $\begin{array}{l}30(28.0 \%) \\
32(29.9 \%)\end{array}$ & \multirow[t]{4}{*}{0.13} \\
\hline$\$ 51,000-75,000$ & $31(22.3 \%)$ & $14(13.1 \%)$ & \\
\hline$\$ 76,000-100,000$ & $18(12.9 \%)$ & $10(9.3 \%)$ & \\
\hline$\$ 100,000$ & $30(21.6 \%)$ & $21(19.6 \%)$ & \\
\hline \multicolumn{4}{|l|}{ Cancer site $(N, \%)$} \\
\hline $\begin{array}{l}\text { Colon } \\
\text { Rectum }\end{array}$ & $\begin{array}{l}52(36.1 \%) \\
92(63.9 \%)\end{array}$ & $\begin{array}{l}61(52.1 \%) \\
56(47.9 \%)\end{array}$ & 0.01 \\
\hline \multicolumn{4}{|l|}{ Type of resection $(N, \%)$} \\
\hline $\begin{array}{l}\text { Abdominoperineal resection } \\
\text { Low anterior resection }\end{array}$ & $\begin{array}{l}18(19.1 \%) \\
65(69.2 \%)\end{array}$ & $\begin{array}{l}7(11.1 \%) \\
53(84.1 \%)\end{array}$ & \multirow[t]{3}{*}{0.006} \\
\hline Transanal excision & $11(11.7 \%)$ & $3(4.8 \%)$ & \\
\hline Colectomy & $41(28.4 \%)$ & $51(43.6 \%)$ & \\
\hline Ostomy $^{\mathrm{a}}(N, \%)$ & $29(20.3 \%)$ & $11(9.5 \%)$ & 0.02 \\
\hline \multicolumn{4}{|l|}{ Stage at diagnosis $(N, \%)$} \\
\hline $\begin{array}{l}\text { I } \\
\text { II }\end{array}$ & $\begin{array}{l}26(18.1 \%) \\
55(38.2 \%)\end{array}$ & $\begin{array}{l}13(11.1 \%) \\
50(42.7 \%)\end{array}$ & \multirow[t]{2}{*}{0.47} \\
\hline III & $59(41.0 \%)$ & $50(42.7 \%)$ & \\
\hline Recurrent disease $(N, \%)$ & $10(6.9 \%)$ & $11(9.4 \%)$ & 0.52 \\
\hline Radiotherapy $(N, \%)$ & $93(64.6 \%)$ & $54(46.2 \%)$ & 0.004 \\
\hline Chemotherapy $(N, \%)$ & $115(80.4 \%)$ & $94(80.3 \%)$ & 0.99 \\
\hline
\end{tabular}

more likely to be diagnosed with rectal cancer and to have received APR resection and pelvic radiotherapy.

Descriptive results of sexual function and enjoyment and psychosocial variables

In the current sample, $65.5 \%$ of men reported moderate to severe erectile dysfunction (scores on ED subscale of IIEF $<$
16), and $42.3 \%$ of women revealed sexual dysfunction (scores on FSFI>26.55). Tables 2 and 3 compare the means and standard deviations of the IIEF scores for men and FSFI scores for women in our sample with those from surveys of another cohort of colorectal cancer survivors, prostate or cervical cancer survivors, and healthy community dwellers. Men in our sample had slightly better sexual function/ satisfaction scores than another cohort of colorectal cancer 
Table 2 International index of erectile function scores (mean $\pm \mathrm{SD}$ ) for cohorts of four studies
$I I E F$ international index of erectile function, $S D$ standard deviation

${ }^{\text {a }}$ SDs were not available for the healthy control group

\begin{tabular}{lllll}
\hline & $\begin{array}{l}\text { Current study } \\
(N=131 \text { colorectal } \\
\text { cancer survivors })\end{array}$ & $\begin{array}{l}\text { Hendren et al. } \\
{[4](N=93 \text { rectal }} \\
\text { cancer survivors })\end{array}$ & $\begin{array}{l}\text { Schover et al. } \\
{[47](N=1,099} \\
\text { prostate cancer } \\
\text { survivors })\end{array}$ & $\begin{array}{l}\text { Rosen et al. } \\
{[28](N=109} \\
\text { healthy comparison } \\
\text { cohort })^{\mathrm{a}}\end{array}$ \\
\hline $\begin{array}{l}\text { Mean age (range) } \\
\text { IIEF domain (mean } \pm \mathrm{SD})\end{array}$ & $63.3(37-85)$ & $68(57-75)$ & $68.1(42-88)$ & $55(31-86)$ \\
Erectile function & $12.2 \pm 11.2$ & $10.7 \pm 10.3$ & $9.7 \pm 10.4$ & 25.8 \\
$\begin{array}{l}\text { Orgasmic function } \\
\text { Sexual desire }\end{array}$ & $5.0 \pm 4.3$ & $3.6 \pm 3.9$ & $3.6 \pm 3.7$ & 8.8 \\
Intercourse satisfaction & $5.5 \pm 2.6$ & $4.9 \pm 2.3$ & $5.3 \pm 2.5$ & 7.0 \\
Overall satisfaction & $5.1 \pm 2.8$ & $3.9 \pm 4.9$ & $3.8 \pm 4.8$ & 10.6 \\
Total & $33.6 \pm 23.9$ & $5.0 \pm 2.0$ & $5.0 \pm 2.8$ & 8.6 \\
\hline
\end{tabular}

survivors or a large cohort of prostate survivors but worse scores than a normative sample of healthy men. Female sexual function was poorer than that of healthy comparisons but similar to that in previous surveys of colorectal and cervical cancer survivors. The means and standard deviations of the psychosocial self-report questionnaires are presented in Table 4 for men, women, and the entire sample. Of note, women reported higher levels of depressive symptoms than men $(P<0.003)$. Although there was a significant gender difference in raw scores for the Global Severity Index of the BSI-18, T-scores from norms for oncology patients reveal that means for both men and women were 50 , so no valid gender difference in overall distress was shown.

Bivariate association between demographic and medical factors and sexual outcomes

With older age, IIEF total scores decreased $(r=-0.34, P<$ $0.0001)$, as did FSFI total scores $(r=-0.44, P<0.0001)$ and sexual "function" (frequency) scores for both men and women on the CRC QLQ-38 ( $r=-0.28, P<0.0001)$. Compared to men, women reported less frequent desire and activity (CRC QLQ-38; sexual function scale; women, 20.0 vs. men, $35.8, P<0.0001)$ and less sexual enjoyment (women, 52.0 vs. men, 66.7, $P<0.007$ ). Both men and women in a committed relationship scored higher on the CRC QLQ-38 "sexual function" scale compared to single participants (committed relationship, 40.74 vs. single, $14.15, P<0.0001)$. Yet, marital status was not significantly associated with IIEF or FSFI scores. Education and income were not significantly associated with any sexual outcome. Men who had undergone a colostomy (stoma, 36.89 vs. no stoma, 20.88, $P<0.003$ ) and who were more recently treated $(r=-0.18, P<0.05)$ reported significantly worse functioning on the IIEF. Men who had undergone APR had lower IIEF scores than those who had other resections (APR, 21.13 vs. anterior resections, 34.19, vs. transanal excision, 33.26, vs. colectomy, 42.00; $P<0.05)$. IIEF scores were lower for men who had rectal cancer (rectal, 30.66 vs. colon, 38.80, $P=$ $0.07)$. Women who had received pelvic radiation reported worse functioning on the FSFI (no radiation, 19.79 vs. radiation, $14.15, P<0.05)$ especially dyspareunia as measured by the FISFI pain subscale (no radiation, 1.72 vs. radiation, 2.71). None of the other medical characteristic were significantly associated with sexual outcomes.
Table 3 Female sexual function index scores $($ mean $\pm \mathrm{SD})$ for cohorts of four studies

FSFI female sexual function index, $S D$ standard deviation

${ }^{\text {a }}$ SDs were not available for the healthy control group

${ }^{\mathrm{b}}$ Total score was not available for the healthy cohort

\begin{tabular}{lllll}
\hline & $\begin{array}{l}\text { Current study } \\
(N=97 \text { colorectal } \\
\text { cancer survivors })\end{array}$ & $\begin{array}{l}\text { Hendren et al. [4] } \\
(N=93 \text { rectal } \\
\text { cancer survivors })\end{array}$ & $\begin{array}{l}\text { Serati et al. [48] } \\
(N=38 \text { cervical } \\
\text { cancer survivors })^{\mathrm{a}}\end{array}$ & $\begin{array}{l}\text { Berra et al. [49] } \\
(N=100 \text { healthy } \\
\text { comparison cohort })\end{array}$ \\
\hline $\begin{array}{l}\text { Mean (range) } \\
\text { FSFI domain (mean } \pm \text { SD) }\end{array}$ & $68(53-75)$ & $45(24-69)$ & $54(45-72)$ \\
Desire & $2.1 \pm 1.3$ & $2.4 \pm 1.2$ & 2.6 & $3.0 \pm 1.29$ \\
Arousal & $1.7 \pm 1.8$ & $2.4 \pm 2.2$ & 2.4 & $3.2 \pm 1.69$ \\
Lubrication & $1.7 \pm 2.1$ & $2.3 \pm 2.4$ & 1.5 & $3.6 \pm 1.94$ \\
Orgasm & $1.8 \pm 2.2$ & $2.5 \pm 2.5$ & 3.4 & $3.4 \pm 1.82$ \\
Satisfaction & $3.4 \pm 1.9$ & $3.7 \pm 2.1$ & 3.6 & $3.7 \pm 1.87$ \\
Pain & $2.2 \pm 2.5$ & $2.4 \pm 2.8$ & 3.0 & $3.7 \pm 1.87$ \\
Total & $16.9 \pm 10.6$ & $17.5 \pm 11.9$ & 17.20 & $-{ }^{\mathrm{b}}$ \\
\hline
\end{tabular}


Table 4 Scores on psychosocial questionnaires, by gender and for total sample

\begin{tabular}{|c|c|c|c|c|c|c|c|c|}
\hline \multirow[t]{2}{*}{ Inventory } & \multicolumn{2}{|l|}{ Men } & \multicolumn{2}{|c|}{ Women } & \multicolumn{4}{|c|}{ Total sample } \\
\hline & Mean & SD & Mean & SD & $P$ value & Mean & $\mathrm{SD}$ & Range \\
\hline \multicolumn{9}{|l|}{ EORTC-QLQ-CR38 subscales } \\
\hline Sexual activity $(N=249)$ & 27.3 & 27.6 & 17.6 & 24.8 & 0.005 & 29.0 & 26.0 & $0-100$ \\
\hline Sexual enjoyment $(N=118)$ & 66.7 & 26.5 & 52.0 & 28.9 & 0.007 & 61.6 & 28.1 & $0-100$ \\
\hline Sexual interest $(N=250)$ & 44.3 & 30.3 & 17.8 & 24.8 & $<0.0001$ & 34.4 & 30.5 & $0-100$ \\
\hline Body image $(N=258)$ & 76.7 & 24.4 & 75.4 & 27.8 & 0.699 & 76.1 & 25.9 & $0-100$ \\
\hline Bowel function $(N=202)$ & 19.8 & 16.8 & 18.1 & 16.8 & 0.473 & 19.0 & 16.8 & $0-100$ \\
\hline Stoma function $(N=41)$ & 28.3 & 21.3 & 37.23 & 25.6 & 0.967 & 27.32 & 22.96 & $0-85$ \\
\hline Global QoL $(N=258)$ & 78.7 & 18.7 & 75.1 & 21.8 & 0.161 & 77.1 & 20.3 & $0-100$ \\
\hline CES-D $(N=247)$ & 8.4 & 7.9 & 11.7 & 9.6 & 0.003 & 9.9 & 8.9 & $0-48$ \\
\hline BSI-18 $(N=258)$ & 5.8 & 7.8 & 8.5 & 9.5 & $-^{\mathrm{a}}$ & 7.9 & 8.7 & $0-51$ \\
\hline MOS-SSS $(N=240)$ & 63.2 & 5.4 & 60.0 & 16.3 & 0.121 & 61.8 & 15.8 & $3-76$ \\
\hline A-DAS $(N=191)$ & 25.6 & 5.4 & 24.0 & 7.2 & 0.108 & 32.8 & 23.8 & $5-75$ \\
\hline
\end{tabular}

$S D$ standard deviation, EORTC-QLQ-CR38 European Organization for Research and Treatment of Cancer (EORTC) Colorectal Cancer-Specific Quality of Life Questionnaire, Global QoL global quality of life, CES-D Center for Epidemiological Studies-Depression Scale, BSI-18 GSI raw scores of the Global Severity Index of the Brief Symptom Inventory-18, MOS-SSS Medical Outcomes Study Social Support Survey, A-DAS Abbreviated Dyadic Adjustment Scale

${ }^{a}$ No gender difference score was calculated because the BSI-18 has gender-specific T-scores, and a gender difference based on raw scores would be meaningless. Men's and women's mean T-scores were equivalent

Correlations among sexual and psychosocial variables

Table 5 illustrates that measures of sexuality are moderately to strongly correlated ( $r=0.48$ to $r=0.82, P<0.0001$ ). Both sexual outcome subscales from the CRC QLQ-38, as well as FSFI scores, were significantly associated with global QoL
( $r=0.20$ to $r=0.42, P<0.01)$ so that better sexual function was associated with better QoL. Bowel function was significantly associated with FSFI scores $(r=-0.32, P<0.05)$ so that women with more bowel function problems reported lower FSFI scores. There were also moderate to strong correlations $(r=0.40-0.65, P<0.001)$ between reporting problems

Table 5 Correlation coefficients between sexual outcomes and psychosocial variables

\begin{tabular}{|c|c|c|c|c|c|c|c|c|c|c|c|}
\hline Variable & 1 & 2 & 3 & 4 & 5 & 6 & 7 & 8 & 9 & 10 & 11 \\
\hline 1. BSI $(n=258)$ & - & & & & & & & & & & \\
\hline 2. CES-D $(n=247)$ & $0.84 * * *$ & - & & & & & & & & & \\
\hline 3. MOS-SSS $(n=240)$ & $-0.30 * * *$ & $-0.37 * * *$ & - & & & & & & & & \\
\hline 4. A-DAS $(n=191)$ & $-0.26 * *$ & $-0.30 * * *$ & $0.48 * * *$ & - & & & & & & & \\
\hline 5. Body image $(n=258)$ & $-0.55 * * *$ & $-0.51 * * *$ & $0.25 * *$ & 0.06 & - & & & & & & \\
\hline 6. Global QoL $(n=258)$ & $-0.66 * * *$ & $-0.59 * * *$ & $0.22 *$ & $0.20 * *$ & $0.57 * * *$ & - & & & & & \\
\hline 7. Bowel $^{\mathrm{a}}(n=202)$ & $0.44 * * *$ & $0.40 * * *$ & -0.14 & -0.03 & $-0.49 * * *$ & $-0.50 * * *$ & - & & & & \\
\hline 8. Stoma $^{\mathrm{b}}(n=42)$ & $0.65 * * *$ & $0.62 * * *$ & $-0.32 *$ & -0.30 & $-0.57 * * *$ & $-0.62 * * *$ & NA & - & & & \\
\hline 9. Sex function $(n=237)$ & 0.08 & -0.12 & $0.16^{*}$ & $0.16^{*}$ & 0.07 & $0.20 * *$ & -0.05 & -0.10 & - & & \\
\hline 10. Sex enjoyment $(n=112)$ & $-0.35 * *$ & $-0.41 * * *$ & $0.27 * *$ & $0.27 * *$ & $0.22 *$ & $0.32 * * *$ & -0.15 & -0.24 & $0.53 * * *$ & - & \\
\hline 11. IIEF $(n=131)$ & -0.09 & -0.08 & $0.20 *$ & 0.10 & $0.35 * *$ & 0.11 & -0.14 & 0.14 & $0.62 * * *$ & $0.48 * * *$ & - \\
\hline 12. FSFI $(n=97)$ & -0.19 & -0.18 & -0.01 & 0.13 & 0.22 & $0.42 * *$ & $-0.32 *$ & NA & $0.77 * * *$ & $0.82 * * *$ & NA \\
\hline
\end{tabular}

BSI-18 Brief Symptom Inventory-18, CES-D Center for Epidemiological Studies-Depression Scale, MOS-SSS Medical Outcomes Study Social Support Survey, A-DAS Abbreviated Dyadic Adjustment Scale, Global QoL global quality of life, Bowel bowel function; Stoma stoma function, Sex function sexual functioning, Sex enjoyment sexual enjoyment, IIEF International Index of Erectile Functioning, FSFI Female Sexual Functioning Index, $N A$ data not available

$* P<0.05 ; * * P<0.01 ; * * * P<0.001$

${ }^{a}$ Bowel function was only assessed in participants with intact sphincters

${ }^{\mathrm{b}}$ Stoma function was only assessed in participants with stomas 
with stoma/bowel function and having poorer global QoL and mental health (BSI-18 and CES-D scores) for both men and women.

\section{Multiple regression analyses}

We performed multiple regression analyses for the primary sexual dysfunction outcomes, total IIEF score for men, and total FSFI score for women (Table 6). Demographic, medical, and psychosocial factors that were significantly associated with these two outcomes at $P \leq 0.05$ in the bivariate analyses mentioned above were included in the multiple regression analyses. However, because of the small number of stomas in the current sample ( 25 permanent stomas linked to APR and 15 temporary stomas linked to AR), we did not include stoma as a separate variable in the regression analysis. Instead, we excluded cases with temporary stomas $(n=$ $15)$ to conduct a non-confounded comparison test.

For men, we regressed total IIEF scores on age, time since surgery, type of resection, body image, and social support. The overall model accounted for $31 \%$ of the variance. When examining the significance tests associated with the beta coefficients of the predictor variables, increasing age, lower levels of social support, and having received more destructive surgery (e.g., APR) were significantly associated with poorer male sexual function. In the multiple regression analysis, time since surgery was marginally and body image was not significantly associated with IIEF scores.

For women, we regressed total FSFI scores on age, radiotherapy, global QoL, and bowl function. The overall model accounted for $41 \%$ of the variance. When examining the significance tests associated with the beta coefficients of

Table 6 Multiple regression analyses

\begin{tabular}{lrrll}
\hline Variable & \multicolumn{1}{l}{$B$} & \multicolumn{1}{l}{ SE } & \multicolumn{1}{l}{$\beta$} & $R^{2}$ \\
\hline IIEF $(d f=82)$ & & & & \\
Intercept & 106.68 & 19.27 & & 0.31 \\
Age & -0.67 & 0.23 & $-0.31^{* *}$ & \\
Time since surgery & -0.01 & 0.01 & $0.18^{* * * *}$ & \\
Resection & 4.80 & 1.30 & $0.36^{* * *}$ & \\
Body image & 0.05 & 0.10 & 0.11 & \\
Social support & 0.38 & 0.14 & $0.25^{*}$ & \\
FSFI ( $d f=55)$ & & & & 0.41 \\
Intercept & 29.23 & 9.97 & & \\
Age & -0.41 & 0.12 & $-0.40^{* *}$ & \\
Radiotherapy & -3.33 & 2.75 & -0.16 & \\
Global quality of life & 0.17 & 0.07 & $0.37^{*}$ & \\
Bowel function & 0.00 & 0.09 & 0.00 & \\
\hline$R$
\end{tabular}

$B$ raw estimate, $S E$ standard error of the raw estimate, $\beta$ standardized coefficient, IIEF International Index of Erectile Functioning, FSFI Female Sexual Functioning Index, $d f$ degrees of freedom

$* P<0.05 ; * * P<0.01 ; * * * P<0.001 ; * * * * P=0.07$ the predictor variables, increasing age and worse global QoL were significantly associated with poorer female sexual function. Surprisingly, radiotherapy and bowel function were not significantly associated with FSFI scores in the multiple regression analysis.

\section{Discussion}

We examined the relative contribution of demographic, medical, and psychosocial risk factors to self-reported sexual function in a large sample of survivors of colorectal cancer. Of note, in the current study, sexual dysfunction was high in both men and women. As in past studies [4, 11], a strong correlate of sexual problems in men and women was older age, even when medical and psychosocial factors were included in the multiple regression models. Not surprisingly, our results suggest that men who received more destructive surgery (i.e., APR) are more likely to report sexual dysfunction. Unfortunately, a too small subset of men had undergone a colostomy that was not associated with APR so that it was not possible or meaningful to examine the relative contribution of APR per se versus having received a stoma in the multiple regression analyses. For women, neither having a stoma nor type of resection was significantly related to sexual dysfunction. Even though worse outcomes are often reported for rectal compared to colon cancer patients [38], we did not find a significant difference between females with a history of rectal versus colon cancer regarding their FSFI scores. In fact, the FSFI scores in our sample were quite similar to those reported in the cohort of rectal cancer patients of Hendren et al. [4]. Compared to scores of healthy females of similar ages, dyspareunia and inhibited orgasm were particularly severe in women with colorectal cancer [39].

A complex association appears to exist between pelvic radiotherapy, poor bowel function, and female sexual dysfunction. Radiotherapy and bowel function were each independently associated with decreased FSFI scores in the bivariate analyses. However, because both factors were highly correlated with each other $(r=0.47)$ and bowel function with QoL $(r=-0.50)$, they did not uniquely explain variance regarding sexual dysfunction scores when controlling for women's global QoL in the multiple regression model. Consequently, we suggest that pelvic irradiation may impair sexual functioning not only directly by causing vulvovaginal atrophy as has been previously suggested but also indirectly through fecal incontinence associated with rectal damage, a major QoL concern [9]. Even though sexual and anorectal dysfunctions are well recognized treatment side effects, more research is needed on symptoms such as fecal incontinence during sexual activity.

We were particularly interested in the role of psychosocial variables in sexual dysfunction. Interestingly, mental health 
and marital satisfaction were not significantly associated with IIEF or FSFI scores. Further, even though conventional wisdom suggests that impaired body image after cancer is a major cause regarding sexual dysfunction, when age and medical factors were controlled for, body image no longer contributed significantly to the variance in IIEF scores. Distress associated with having a colostomy or having bowel incontinence may be more important in causing sexual problems than "body image," which is typically measured by items self-rating sexual attractiveness [21, 40-42]. In contrast, lack of social support was associated with poorer IIEF scores even when age and medical factors were controlled for. Perhaps the closer association between social support and sexual function in men than in women may reflect men's greater dependence on dyadic relationships [43, 44]. For women, global QoL remained significantly associated with FSFI scores in the multivariate model. As mentioned above, this finding may possibly be explained with radiotherapy-induced bowel problems undermining women's QoL. Based on these findings, we argue that the role of psychosocial factors is limited, and the underlying issues in sexual dysfunction appear to be destructive surgery in men and pelvic radiotherapy in women in addition to older age.

Although this survey was cross-sectional, the correlations observed could help identify men and women at high risk of sexual dysfunction after cancer treatment. Based on our findings, patients who are older or have undergone more destructive cancer treatment (APR in men, adjuvant pelvic radiation in women) are at higher risk of developing sexual dysfunction. Half of the survivors had received surgery at least 2 years prior to data collection, so our findings reinforce the observations that treatment-related sexual dysfunction tends to be long lasting and unlikely to resolve on its own $[7-10,21]$. Because of the exploratory nature of this work, clinical recommendations are clearly premature. However, it is appropriate to highlight the importance of patient-provider communication regarding sexuality in this population. In a very recent study, $55 \%$ of colorectal patients $(N=98)$ indicated that they did not receive any information regarding how cancer treatment may affect their sex life, $71 \%$ of patients did not ask their oncologist about concerns about sexuality, and over $50 \%$ of patients indicated that they would consider it helpful if their oncologist would address this issue [45]. Consequently, we recommend that surgeons and radiation oncologists take an active role in adequately preparing patients regarding treatment-related sexual dysfunction prior to treatment and in identifying patients' sexual dysfunction after treatment [46]. Screening patients routinely during follow-up visits and referring them to sexual rehabilitation services if needed and desired may be essential to providing supportive care for this population.

This study has limitations. The cross-sectional design does not allow inferences about the causality of the observed associations; only a prospective study could determine the direction of causality. Collecting data on sexual dysfunction prior to treatment is important to gaining a better understanding of these associations. The small number of patients with APR or surgery for anal cancer did not allow optimal power in comparing them with participants who had sphincter-saving anterior resections. Our sample was predominately Caucasian; it is not clear whether the associations of psychosocial variables hold true in ethnical minorities. In contrast, this cohort was rather heterogeneous regarding medical characteristics including patients with recurrent disease and only half of the sample having received adjuvant radiotherapy; however, heterogeneity allowed for group comparisons and increased the generalizability of our findings. No data were collected on survivors who declined to participate, so comparison analyses between participants and refusers could not be performed. Some caution in interpreting the current findings is warranted because the combination of two recruitment methods (clinic visits and mailing), with differential response rates, may have introduced a potential sampling bias. However, the majority of the sample (80 \%) came from data collected during clinic visits, which had a high response rate (90\%) and, therefore, any bias would be small. Even though the response rate of the mailed surveys was modest ( $22 \%$ ), which is not uncommon in the sexual dysfunction literature, unlike previous research, we did not exclude sexually inactive survivors [16]. Consequently, we believe the current sample to be fairly representative of a broad range of colorectal cancer survivors.

\section{Conclusion}

This study examined sexual dysfunction and its risk factors in a large cohort of male and female colorectal cancer survivors. The use of well-validated indices of sexual dysfunction allowed for cross-study comparison. Multiple regression analyses to test for unique associations between demographic, medical, and psychosocial factors and sexual function were performed. The study highlights that patients' age and more destructive procedures are related to poorer outcomes. Even though some psychosocial variables (e.g., social support) may also play a role in sexual dysfunction, their contribution is relatively small. The findings are discussed in terms of the need for open patient-provider communication regarding treatment-related sexual dysfunction before and after cancer treatment.

Acknowledgment This study was supported by a supplement to grant NIMH/NCI R01 MH59432.

Conflicts of interest The authors have no conflict of interest to disclose. All authors have full control of all primary data and agree to allow the journal to review their data if requested. 


\section{References}

1. American Cancer Society (2011) Cancer facts \& figures 2011. American Cancer Society, Atlanta

2. Centers for Disease Control and Prevention (2007) Cancer survivors-United States. MMWR 60:269-272

3. Jansen L et al (2010) Quality of life among long-term $(>/=5$ years) colorectal cancer survivors-systematic review. Eur J Cancer 46 (16):2879-2888

4. Hendren SK et al (2005) Prevalence of male and female sexual dysfunction is high following surgery for rectal cancer. Ann Surg 242(2):212-223

5. Denlinger CS, Barsevick AM (2009) The challenges of colorectal cancer survivorship. J Natl Compr Canc Netw 7(8):883-893, quiz 894

6. Ho VP et al (2011) Sexual function after treatment for rectal cancer: a review. Dis Colon Rectum 54(1):113-125

7. Arndt V et al (2006) Restrictions in quality of life in colorectal cancer patients over 3 years after diagnosis: a population based study. Eur J Cancer 42(12):1848-1857

8. Camilleri-Brennan J, Steele RJ (2001) Prospective analysis of quality of life and survival following mesorectal excision for rectal cancer. Br J Surg 88(12):1617-1622

9. Allal AS et al (2005) Assessment of quality of life in patients with rectal cancer treated by preoperative radiotherapy: a longitudinal prospective study. Int J Radiat Oncol Biol Phys 61(4):1129-1135

10. Marijnen CA et al (2005) Impact of short-term preoperative radiotherapy on health-related quality of life and sexual functioning in primary rectal cancer: report of a multicenter randomized trial. J Clin Oncol 23(9):1847-1858

11. Vironen JH et al (2006) Impact of functional results on quality of life after rectal cancer surgery. Dis Colon Rectum 49(5):568-578

12. Maurer CA et al (2001) Total mesorectal excision preserves male genital function compared with conventional rectal cancer surgery. Br J Surg 88(11):1501-1505

13. Ameda $\mathrm{K}$ et al (2005) The long-term voiding function and sexual function after pelvic nerve-sparing radical surgery for rectal cancer. Int J Urol 12(3):256-263

14. Bonnel C et al (2002) Effects of preoperative radiotherapy for primary resectable rectal adenocarcinoma on male sexual and urinary function. Dis Colon Rectum 45(7):934-939

15. Schmidt CE et al (2005) Ten-year historic cohort of quality of life and sexuality in patients with rectal cancer. Dis Colon Rectum 48 (3):483-492

16. Guren MG et al (2005) Quality of life and functional outcome following anterior or abdominoperineal resection for rectal cancer. Eur J Surg Oncol 31(7):735-742

17. Engel J et al (2003) Quality of life in rectal cancer patients: a fouryear prospective study. Ann Surg 238(2):203-213

18. Pachler J, Wille-Jorgensen P (2004) Quality of life after rectal resection for cancer, with or without permanent colostomy. Cochrane Database Syst Rev 3:CD004323

19. Heriot AG et al (2005) Adjuvant radiotherapy is associated with increased sexual dysfunction in male patients undergoing resection for rectal cancer: a predictive model. Ann Surg 242(4):502-510, discussion $510-511$

20. Thong $M$ et al (2011) Impact of preoperative radiotherapy on general and disease-specific health status of rectal cancer survivors: a population study. Int J Radiat Oncol Biol Phys 81(3):e49-58

21. Sadovsky R et al (2010) Cancer and sexual problems. J Sex Med 7 (1 Pt 2):349-373

22. Jayne DG et al (2005) Bladder and sexual function following resection for rectal cancer in a randomized clinical trial of laparoscopic versus open technique. Br J Surg 92(9):1124-1132
23. Engel $\mathrm{J}$ et al (2003) The process of metastasisation for breast cancer. Eur J Cancer 39(12):1794-1806

24. Mannaerts GH et al (2001) Urologic and sexual morbidity following multimodality treatment for locally advanced primary and locally recurrent rectal cancer. Eur J Surg Oncol 27(3):265-272

25. Tekkis PP et al (2009) Measuring sexual and urinary outcomes in women after rectal cancer excision. Dis Colon Rectum 52(1):46-54

26. Schmidt $C$ et al (2010) Sexual impairment and its effects on quality of life in patients with rectal cancer. Dtsch Arztebl Int 107(8):123-130

27. Lynch HT, Lynch JF, Attard TA (2009) Diagnosis and management of hereditary colorectal cancer syndromes: Lynch syndrome as a model. CMAJ 181(5):273-280

28. Rosen RC, Cappelleri JC, Gendrano N 3rd (2002) The international index of erectile function (IIEF): a state-of-the-science review. Int J Impot Res 14(4):226-244

29. Badr H, Carmack-Taylor CL (2009) Sexual dysfunction and spousal communication in couples coping with prostate cancer. Psychooncology 18(7):735-746

30. Wiegel M, Meston C, Rosen R (2005) The female sexual function index (FSFI): cross-validation and development of clinical cutoff scores. J Sex Marital Ther 31(1):1-20

31. Sprangers MA, te Velde A, Aaronson NK (1999) The construction and testing of the EORTC Colorectal Cancer-Specific Quality of Life Questionnaire module (QLQ-CR38). European Organization for Research and Treatment of Cancer Study Group on Quality of Life. Eur J Cancer 35(2):238-247

32. Radloff L (1977) The CES-D scale: a self-report depression scale for research in the general population. Appl Psychol Meas 1(3):385-401

33. Zabora $\mathrm{J}$ et al (2001) A new psychosocial screening instrument for use with cancer patients. Psychosomatics 42(3):241-246

34. Sherbourne CD, Stewart AL (1991) The MOS social support survey. Soc Sci Med 32(6):705-714

35. Hunsley J, Best M, Lefebvre M, Vito D (2001) The seven item short form of the dyadic adjustment scale: further evidence for the construct validity. Am J Fam Ther 29:325-335

36. Cohen J, Cohen P (1983) Applied regression/correlation analysis for the behavioral sciences, 2nd edn. Lawrence Erlbaum Associates, Hillsdale

37. Lindau ST, Gavrilova N (2010) Sex, health, and years of sexually active life gained due to good health: evidence from two US population based cross sectional surveys of ageing. BMJ 340:c810

38. Bohm G et al (2008) Anorectal, bladder, and sexual function in females following colorectal surgery for carcinoma. Int J Color Dis 23(9):893-900

39. Meston C, Trapnell P (2005) Development and validation of a five-factor sexual satisfaction and distress scale for women: the Sexual Satisfaction Scale for Women (SSS-W). J Sex Med 2(1):66-81

40. Canada AL et al (2005) Pilot intervention to enhance sexual rehabilitation for couples after treatment for localized prostate carcinoma. Cancer 104(12):2689-2700

41. Scott JL, Kayser K (2009) A review of couple-based interventions for enhancing women's sexual adjustment and body image after cancer. Cancer J 15(1):48-56

42. Huyghe E et al (2009) Needs assessment survey to justify establishing a reproductive health clinic at a comprehensive cancer center. J Sex Med 6(1):149-163

43. Iecovich E, Jacobs JM, Stessman J (2011) Loneliness, social networks, and mortality: 18 years of follow-up. Int J Aging Hum Dev 72(3):243-263

44. Rendall MS et al (2011) The protective effect of marriage for survival: a review and update. Demography 48(2):481-506

45. Flynn KE et al (2012) Patient experiences with communication about sex during and after treatment for cancer. Psychooncology 21(6):594-601 
46. Park ER, Norris RL, Bober SL (2009) Sexual health communication during cancer care: barriers and recommendations. Cancer J 15(1):74-77

47. Schover LR et al (2002) Defining sexual outcomes after treatment for localized prostate carcinoma. Cancer 95 (8):1773-1785
48. Serati M et al (2009) Sexual function after radical hysterectomy for early-stage cervical cancer: is there a difference between laparoscopy and laparotomy? J Sex Med 6(9):2516-2522

49. Berra $M$ et al (2010) The impairment of sexual function is less distressing for menopausal than for premenopausal women. J Sex Med 7(3):1209-1215 